Article

\title{
Single Crystalline Iron Silicide and Beta-Iron Disilicide Nanowires Formed through Chemical Vapor Deposition
}

\author{
Wei-Jie Huang ${ }^{1}$, Yu-Yang Chen ${ }^{1}$, Hsiu-Ming Hsu ${ }^{1}$ and Kuo-Chang Lu ${ }^{1,2, *}$ \\ 1 Department of Materials Science and Engineering, National Cheng Kung University, Tainan 701, Taiwan; \\ ecao1ah@hotmail.com (W.-J.H.); yuyang840228@gmail.com (Y.-Y.C.); hpolokoio@gmail.com (H.-M.H.) \\ 2 Center for Micro/Nano Science and Technology, National Cheng Kung University, Tainan 701, Taiwan \\ * Correspondence: gkclu@mail.ncku.edu.tw; Tel.: +886-6-275-7575\#62920
}

Received: 3 November 2018; Accepted: 23 November 2018; Published: 27 November 2018

\begin{abstract}
In this paper, we report the synthesis of iron silicide and $\beta$-iron disilicide nanowires with chemical vapor deposition; remarkably, the latter has drawn much attention but has seldom been achieved. We also propose the formation mechanisms for the two phases. To investigate the effects of the growth parameters on compositions and morphologies of the iron silicide nanowires, we changed and studied the reaction time, substrate temperature, position of samples, and pressure. The reaction concentration was found to be altered by all of the parameters; thus, we observed different nanowires in terms of morphologies and compositions with scanning electron microscopy. To confirm the growth direction and crystal structure of the nanowires, we conducted x-ray diffraction and high-resolution transmission electron microscopy studies. With the potential of being utilized as circuit elements in electronic devices for Schottky barriers, ohmic contacts, and interconnection among silicon-based transistors, the silicide work at nanoscale is beneficial for nanoelectronics. Understanding the effects of these growth parameters facilitates the control of nanowire growth with better quality.
\end{abstract}

Keywords: $\beta-\mathrm{FeSi}_{2} ; \mathrm{FeSi}$; chemical vapor deposition; nanowires; transmission electron microscopy

\section{Introduction}

For the miniaturization of electronic devices, various materials are being studied for their promising applications. Graphene- $\mathrm{ZnO}$ nanoparticles were investigated for being applied in light-emitting diodes and photodetectors [1]. $\mathrm{Fe}^{3+}$-doped $\mathrm{PbTiO}_{3}$ nanocrystals were studied systematically for better understanding of this novel material [2]. Growing various iron oxides' thin films with different precursors via the chemical vapor deposition (CVD) method was conducted [3]. Metal silicide technology has also attracted lots of interest for their distinct physical properties, as compared with materials in bulk and thin film. Transition-metal silicides have been studied extensively [4-10]. NiSi, $\mathrm{TiSi}_{2}, \mathrm{CoSi}_{2}$ and their excellent properties, such as low resistivity, high melting-point, and good stability, are generally used for metal-gate materials to reduce resistance in virtue of their low resistivity [11]. $\mathrm{MnSi}, \beta-\mathrm{FeSi}_{2}$, and $\mathrm{CrSi}_{2}$ are great thermoelectric materials as a result of their good thermostability and narrow energy gap [12]. Metal silicide thin films can also be applied in electronic junctions and interconnecting devices. There are different metals that can be used for silicide applications based on their different properties, such as their silicidation temperatures, resistivities, dominant-diffusing species, and etching capabilities.

One-dimensional nanostructures are promising for bottom-top microelectronics devices due to their novel properties, such as electrical properties, low defect density, and high compatibility [13], emerging as materials for academic study and technological applications [14]. Methods of nanowire synthesis have been studied for years. There are many approaches for synthesizing metal silicide 
nanowires (NWs). For example, NiSi NWs were synthesized by the chemical reaction between silicon NWs and nickel NWs. Nickel silicide NWs were also obtained by decomposition of silane on nickel substrates [15]. Chemical vapor deposition is another well-known method; although the reaction may seem simple, professional experiences are necessary for choosing appropriate precursors and controlling the reaction conditions; the morphology of the materials is very sensitive to temperature and the deposition position is a function of the flow rate, deposition temperature, and pressure. In recent years, growth of a variety of metal silicide NWs, ranging from transition metal silicides to rare-earth silicides, has been reported [16-20]. These silicide NWs were grown by first depositing an appropriate metal film on a Si substrate, followed by heat treatment. On the other hand, some growth methods have been reported for forming free-standing silicide NWs. Ouyang et al. used $\mathrm{FeCl}_{3}$ powders to grow $\varepsilon$-FeSi NWs on a Si wafer in an alumina tube furnace via Vapor-Phase Synthesis [21]. In addition, Schmitt et al. used a new method to produce free-standing, single-crystal FeSi NWs through organometallic precursor trans- $\mathrm{Fe}\left(\mathrm{SiCl}_{3}\right)_{2}(\mathrm{CO})_{4}$ in a simple CVD process [22].

In this work, we demonstrate the synthesis of single-crystalline $\mathrm{FeSi}$ and $\beta-\mathrm{FeSi}_{2}$ nanowires by CVD. Iron disilicide has been studied recently since there are numerous specific phases in iron disilicide. $\alpha$-FeSi 2 , which is stable at temperatures ranging from $950{ }^{\circ} \mathrm{C}$ up to about $1250{ }^{\circ} \mathrm{C}$, has a tetragonal structure with lattice parameters of $\mathrm{a}=\mathrm{b}=2.684 \AA$ and $\mathrm{c}=5.124 \AA$, possessing a metallic property. $\beta-\mathrm{FeSi}_{2}$ has an orthorhombic structure with lattice parameters of $\mathrm{a}=9.863 \AA, \mathrm{b}=7.791 \AA$, and $\mathrm{c}=7.833 \AA$, being a semiconductor stably below $950{ }^{\circ} \mathrm{C}$ [23]. In addition to these two stable phases, there are two other metastable metallic $\mathrm{FeSi}_{2}$ phases. $\gamma$ - $\mathrm{FeSi}_{2}$, is metallic and magnetic, having a FCC structure with lattice parameters of $\mathrm{a}=5.389 \AA$. Although s-FeSi $i_{2}$ is metallic structured, it has a BCC structure with lattice parameters of $a=2.7 \AA$ [24-27]. FeSi is a narrow-band gap semiconductor with a cubic structure, where $\mathrm{a}=\mathrm{b}=\mathrm{c}=4.485 \AA$, and has been classified as a Kondo insulator.

The unusual features of $\beta-\mathrm{FeSi}_{2}$ is of particular interest. $\beta-\mathrm{FeSi}_{2}$ nanowires and their applications on communication were reported [28]; however, there have been difficulties in forming $\beta$ - $\mathrm{FeSi}_{2}$ nanowires through chemical vapor deposition. The room-temperature equilibrium phase, $\beta-\mathrm{FeSi}_{2}$, has a direct band gap, making it a promising choice in infrared detectors and light emitters for silicon-based optoelectronics. Recently, the use of magnetic semiconducting silicide, $\mathrm{Fe}_{1-x} \mathrm{Co}_{x} \mathrm{Si}$, as injectors for spintronics applications has been reported [29]. In this study, we report efficient synthesis and structural characterization of the single crystalline $\beta-\mathrm{FeSi}_{2}$ nanowires via chemical vapor deposition.

\section{Materials and Methods}

Figure 1 is the schematic illustration of the experimental procedures. In this work, the synthesis of $\beta-\mathrm{FeSi}_{2}$ and $\mathrm{FeSi}$ nanowires was conducted in a conventional three-zone furnace through chemical vapor deposition. The furnace has a structure of double-layer quartz tubes; the diameter of the inner tube is $50 \mathrm{~mm}$, while that of the outer tube is $75 \mathrm{~mm}$, and both tubes are $120 \mathrm{~cm}$ long. Firstly, single-crystalline Si (100) substrates were cut into $2 \mathrm{~cm} \times 2 \mathrm{~cm}$ and were cleaned in acetone and isopropyl alcohol with ultrasonication. To remove the native oxide layer, substrates were dipped in dilute $\mathrm{HF}$ for $5 \mathrm{~min}$; then, they were put into crucibles A, B, and C. Crucible A was located in the middle of the second heating zone, and crucible $C$ was in the middle of the third heating zone. Crucible $B$ was between crucible A and C. Anhydrous iron chloride powders, as precursors in our work, were placed in an alumina boat, upstream of the first heating zone. The distance away from the precursor for crucibles A, B, and C was 20,30, and $40 \mathrm{~cm}$, respectively. To understand the factors that influence the growth of iron silicide nanowires, processing parameters, including the temperature, pressure, and gas flow-rate were varied and studied. We utilized X-ray diffraction (XRD, D8 discover with GADDS, Bruker AXS Gmbh, Karlsruhe, Germany) and transmission electron microscope (TEM, JEM-1400, JOEL, Akishima, Japan) for structural characterization and composition analysis. Field emission scanning electron microscope (FESEM, SU8000, Hitachi, Tokyo, Japan) was utilized for the morphology. 


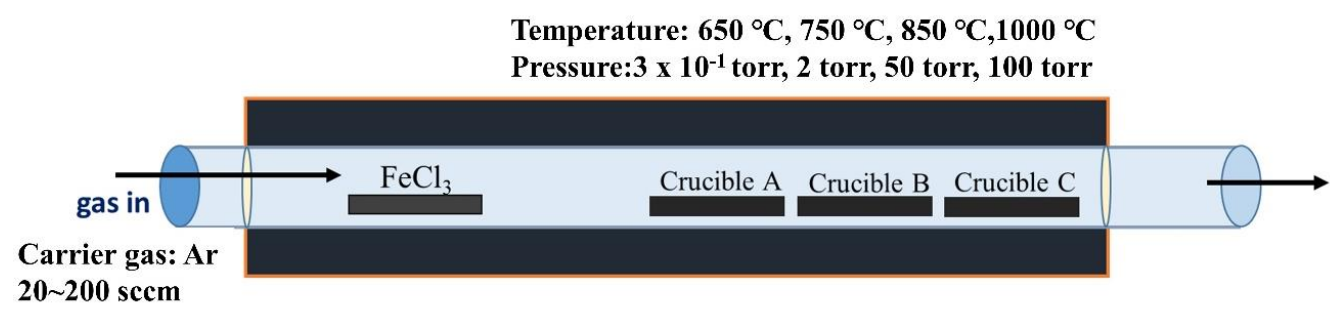

Figure 1. Schematic illustration of the CVD system, with $\mathrm{FeCl}_{3}$ as precursors.

\section{Results and Discussion}

\subsection{Morphology}

\subsubsection{Temperature}

All samples were collected from crucible B. Figure 2a-d shows the SEM images of samples grown at different temperatures $\left(650^{\circ} \mathrm{C}, 750{ }^{\circ} \mathrm{C}, 850^{\circ} \mathrm{C}\right.$, and $1000^{\circ} \mathrm{C}$, respectively) for $2 \mathrm{~h}$, where the ambient pressure was $3 \times 10^{-1}$ torr, and the flow rate was fixed at $20 \mathrm{sccm}$. Figure $2 \mathrm{a}$ shows the case at $650{ }^{\circ} \mathrm{C}$, where no NWs but thin films were grown on the substrate. Figure $2 \mathrm{~b}$ shows the case at $750{ }^{\circ} \mathrm{C}$, where the NWs were short in length with typical diameters ranging from 70 to $100 \mathrm{~nm}$. When we raised the temperature to $850{ }^{\circ} \mathrm{C}$ as shown in Figure 2c, NWs with the highest aspect ratio and of about 20 to $40 \mathrm{~nm}$ in diameter were obtained. Figure $2 \mathrm{~d}$ shows the case at $1000{ }^{\circ} \mathrm{C}$, where thin films with coarse grains were found on the substrates. At high temperatures, it was easy for the precursor to transform into the vapor phase and be transported to the crucibles; thus, the reaction concentration was increased. With high reaction concentration, the growth rate was fast, changing the morphology of the samples from nanowires to thin film. On the other hand, the reaction rate was slow at $650{ }^{\circ} \mathrm{C}$, and the duration time of $2 \mathrm{~h}$ was too short for NWs growth; as a result, no nanowires appeared at $650{ }^{\circ} \mathrm{C}$. Therefore, we found that the best growth temperatures here were $700-850{ }^{\circ} \mathrm{C}$.
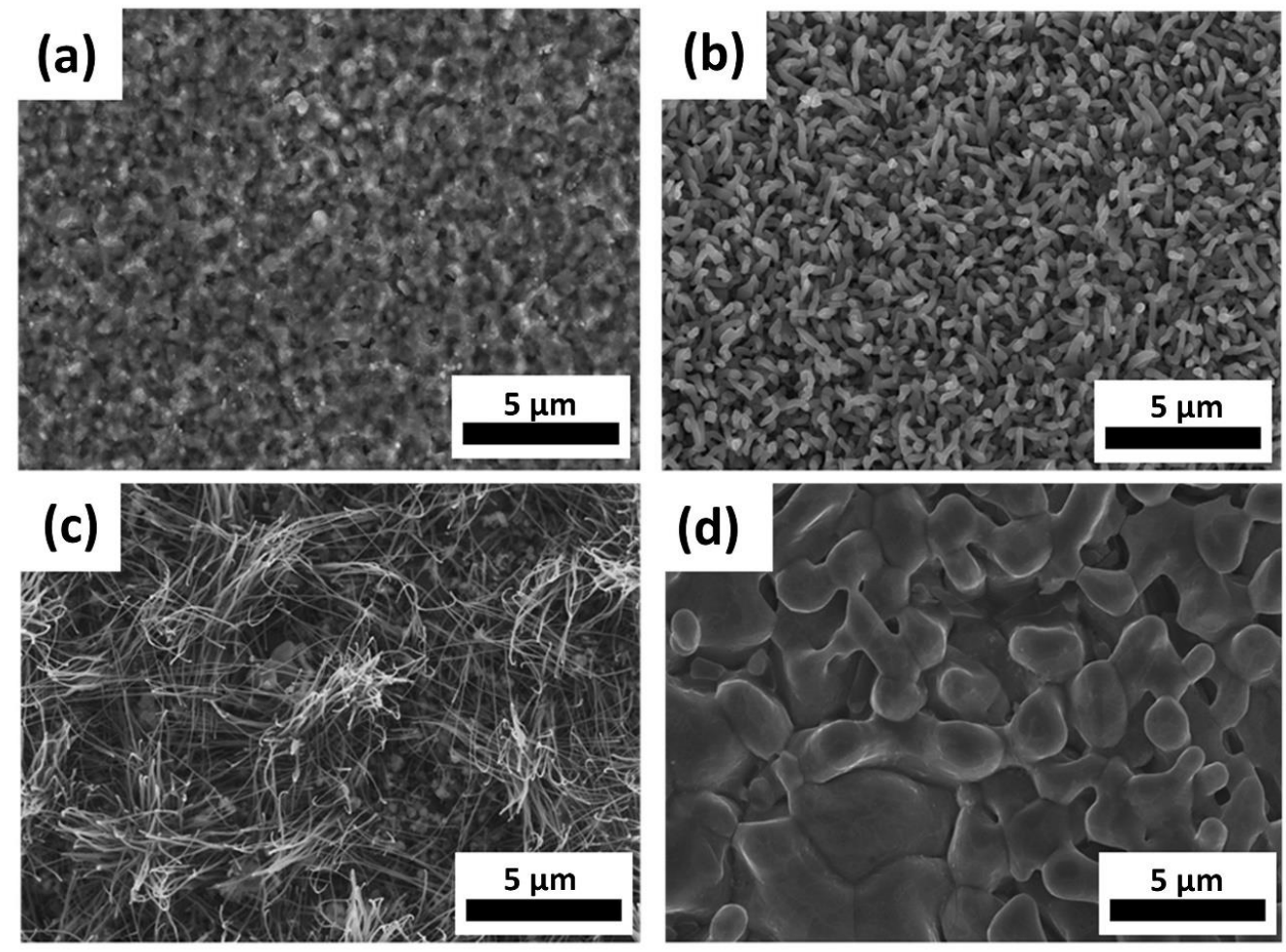

Figure 2. SEM images of samples grown at (a) $650{ }^{\circ} \mathrm{C}$, (b) $750{ }^{\circ} \mathrm{C}$, (c) $850{ }^{\circ} \mathrm{C}$, and (d) $1000{ }^{\circ} \mathrm{C}$ at $3 \times 10^{-1}$ torr for $2 \mathrm{~h}$. 


\subsubsection{Pressure and Flow Rate}

The second parameter we investigated was the pressure. Figure 3a-d shows the SEM images for $3 \times 10^{-1}, 2,50$, and 100 torr, respectively. While we conducted the experiment, the temperature was kept at $850{ }^{\circ} \mathrm{C}$ for $2 \mathrm{~h}$, and the gas flow-rate was $20 \mathrm{sccm}$. The diameter of NWs grown at $3 \times 10^{-1}$ torr was 20 to $40 \mathrm{~nm}$, while that of nanowires grown at 100 torr was 100 to $150 \mathrm{~nm}$ with the decrease of the density. The diameter of the NWs increased as the pressure was increased. This was due to the fact that at high ambient pressure, the vapor pressure of the precursor was low, which caused the lower reaction concentration. In our experiment, the pressure was controlled by the partial pressure of Ar, and the effect of ambient pressure could be explained by Rault's law:

$$
\begin{gathered}
\mathrm{P}=\mathrm{P}_{\mathrm{Ar}}^{*} \times \mathrm{X}_{\mathrm{Ar}}+\mathrm{P}_{\mathrm{FeCl}_{3}}^{*} \times \mathrm{X}_{\mathrm{FeCl}_{3}} \\
\Delta \mathrm{P}_{\mathrm{FeCl}_{3}}=\mathrm{P}_{\mathrm{FeCl}_{3}}^{*} \times \mathrm{X}_{\mathrm{FeCl}_{3}}
\end{gathered}
$$

where $\mathrm{P}$ is the ambient pressure in the furnace, $\mathrm{P}_{\mathrm{Ar}}^{*}$ is the saturated vapor pressure of $\mathrm{Ar}, \mathrm{P}_{\mathrm{FeCl}_{3}}^{*}$ is the saturated vapor pressure of $\mathrm{FeCl}_{3}, \mathrm{X}_{\mathrm{Ar}}$ is the mole fraction of $\mathrm{Ar}, \mathrm{X}_{\mathrm{FeCl}_{3}}$ is the mole fraction of $\mathrm{FeCl}_{3}$, and $\Delta \mathrm{P}_{\mathrm{FeCl}_{3}}$ is the change of the partial pressure of $\mathrm{FeCl}_{3}$. In our study, the increase of the ambient pressure was achieved by the large quantity of Ar. Therefore, the mole fraction of $\mathrm{FeCl}_{3}$ and its partial pressure decreased with the increase of Ar. Through ideal gas function, the gas concentration is directly proportional to the pressure. The decrease of $\mathrm{FeCl}_{3}$ vapor pressure suggested that the concentration of $\mathrm{FeCl}_{3}$ became lower. The free energy of nucleation is a function of the reaction concentration.

$$
\Delta \mathrm{G}=-\frac{\mathrm{kT}}{\Omega} \ln \left(\frac{\mathrm{C}}{\mathrm{C}_{0}}\right)
$$

where $\Delta \mathrm{G}$ is the free energy for nucleation, $\mathrm{T}$ is the temperature, $\Omega$ is the atomic volume, $\mathrm{C}$ is the reaction concentration, and $\mathrm{C}_{0}$ is the equilibrium reaction concentration. The decrease of the reaction concentration reduced the free energy for nucleation in $\mathrm{FeCl}_{3}$, which increased the critical size for nucleation.

$$
\mathrm{r}^{*}=\frac{-2 \gamma}{\Delta \mathrm{G}^{*}}
$$

$\mathrm{r}^{*}$ is the critical radius of nuclei, $\gamma$ is the surface energy, and $\Delta \mathrm{G}^{*}$ is the critical energy for nucleation. As the ambient pressure increased, the reaction concentration was lower and the size of the nuclei became larger, which explains why NWs grown at high ambient pressure possess wider diameters.

Gas flow rate and deposition position are important factors in CVD [30], which would directly affect the distribution of reaction concentration. Figure $4 \mathrm{a}, \mathrm{b}$ show the morphology of samples grown at $850{ }^{\circ} \mathrm{C}$ for $2 \mathrm{~h}$ at the flow rate of 100 and $200 \mathrm{sccm}$, respectively. At high flow rate, most vapor molecules of the precursor were taken away from the quartz tube, and the reaction concentration in the quartz tube was low. Thus, less precursor molecules deposited onto the silicon substrates, contributing to less NW growth. Figure $4 \mathrm{c}$ shows NWs grown at $1000^{\circ} \mathrm{C}$ for $5 \mathrm{~min}$. If we compare with Figure 2d, reducing the reaction time at $1000{ }^{\circ} \mathrm{C}$ would prevent the overreaction of the growth of NWs because the reaction rate at $1000^{\circ} \mathrm{C}$ was very fast. 

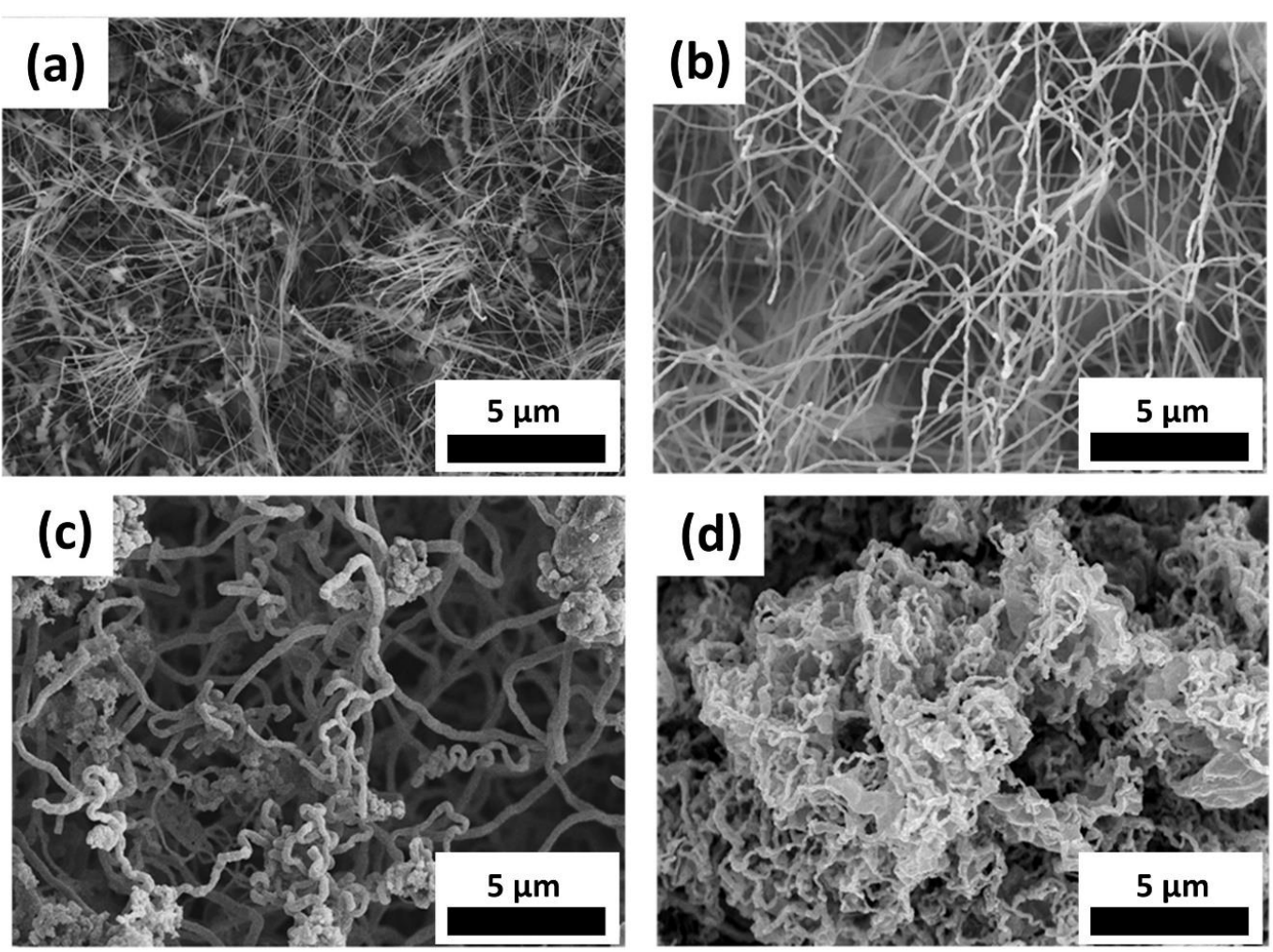

Figure 3. SEM images of samples grown at: (a) $3 \times 10^{-1}$ torr, (b) 2 torr, (c) 50 torr, and (d) 100 torr.
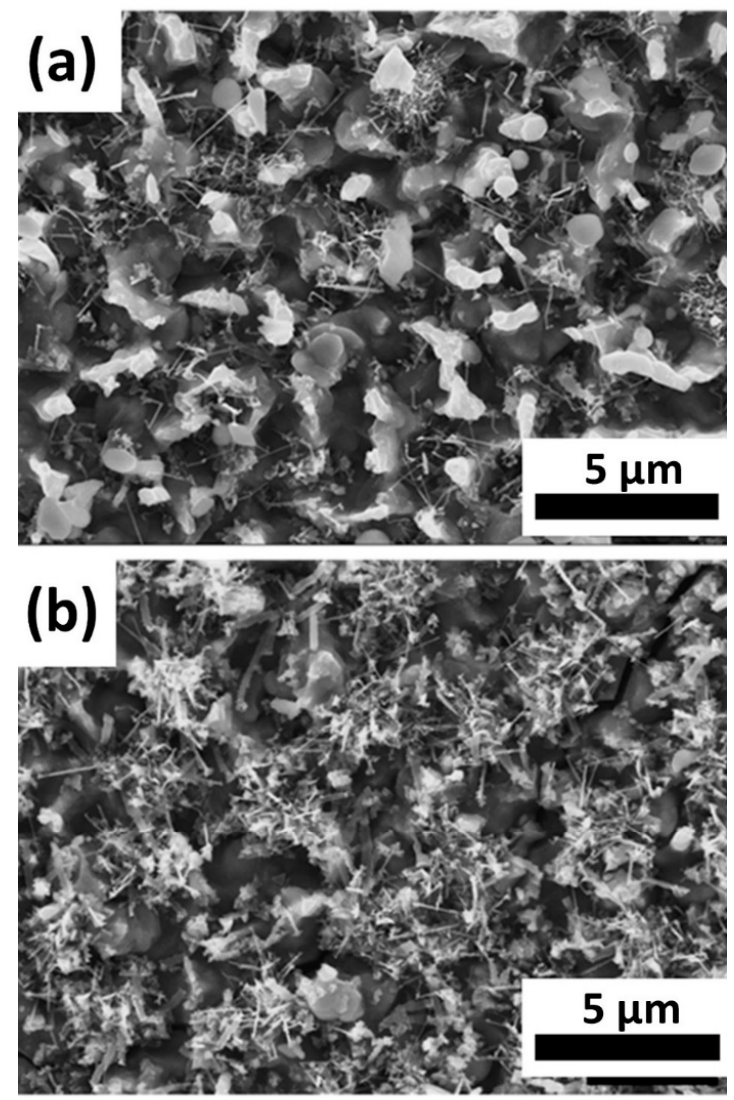

Figure 4. Cont. 


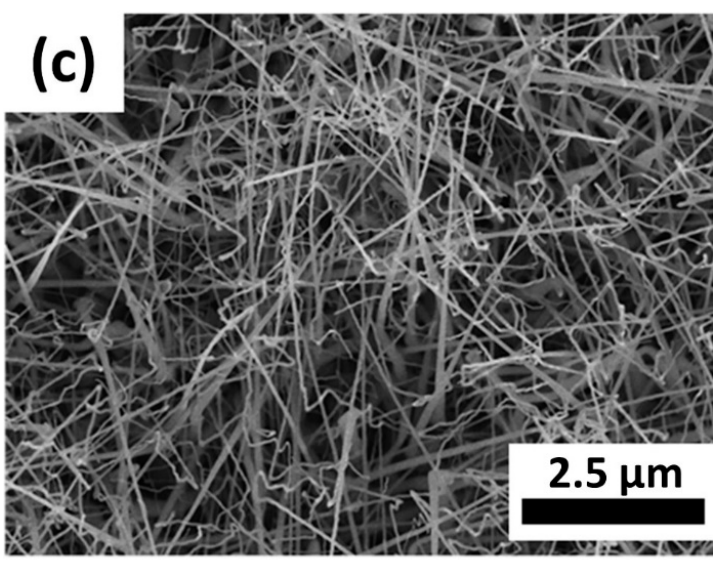

Figure 4. SEM images of nanowires grown at gas flow rates (a) $100 \mathrm{sccm}$ and (b) $200 \mathrm{sccm}$ at $850{ }^{\circ} \mathrm{C}$. (c) SEM image of nanowires grown at $1000^{\circ} \mathrm{C}$ for $5 \mathrm{~min}$.

\subsection{Structure Analysis}

Figure 5a-d are XRD spectra and TEM images of the samples grown at different temperatures and pressures. Figure $5 \mathrm{a}$, the XRD analysis, indicates that $\mathrm{FeSi}$ was formed at $1000{ }^{\circ} \mathrm{C}$, while $\beta-\mathrm{FeSi}_{2}$ was formed at $650{ }^{\circ} \mathrm{C}, 750^{\circ} \mathrm{C}$, and $850^{\circ} \mathrm{C}$. These results are consistent with previous studies [21,31]. Figure $5 \mathrm{~b}$ is the spectrum of NWs grown at different ambient pressures. As the pressure increased, the intensity of the characteristic peak (211) was reduced, which suggested the content of FeSi was lower at a higher pressure. Figure 5c,d are a low-magnification TEM image, HR-TEM image, and diffraction pattern of nanowires grown at $1000^{\circ} \mathrm{C}$ for $5 \mathrm{~min}$ and $850^{\circ} \mathrm{C}$ for $2 \mathrm{~h}$, respectively. Through the TEM analysis, the growth direction, which was [111] for $\mathrm{FeSi}$ and [202] for $\beta-\mathrm{FeSi}_{2}$, and the lattice structures, were confirmed. At higher temperatures, NWs were single crystalline, while at lower temperatures, the crystallinity of the NWs was worse. Additionally, we found that the impact of the temperature was larger than that of the pressure.
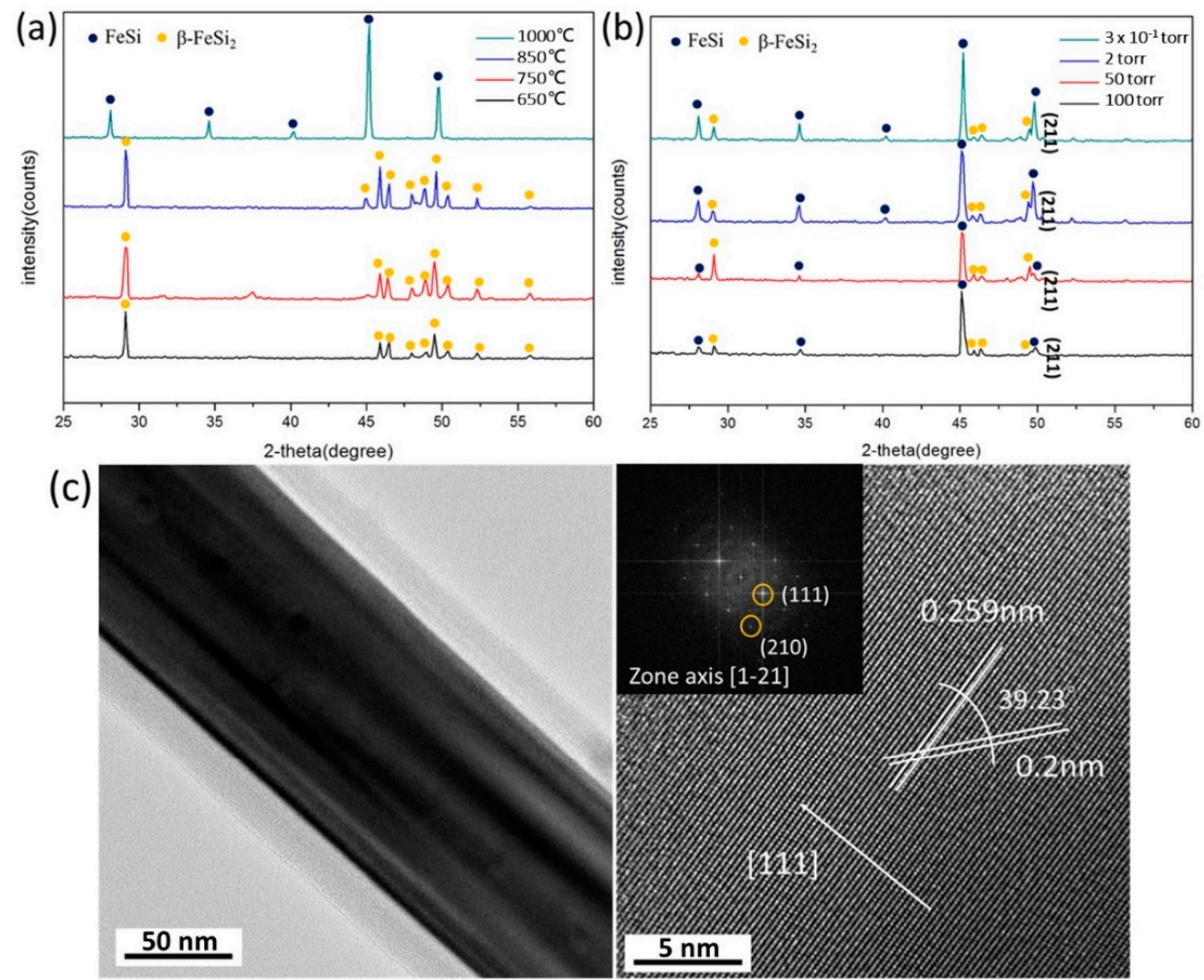

Figure 5. Cont. 
(d)
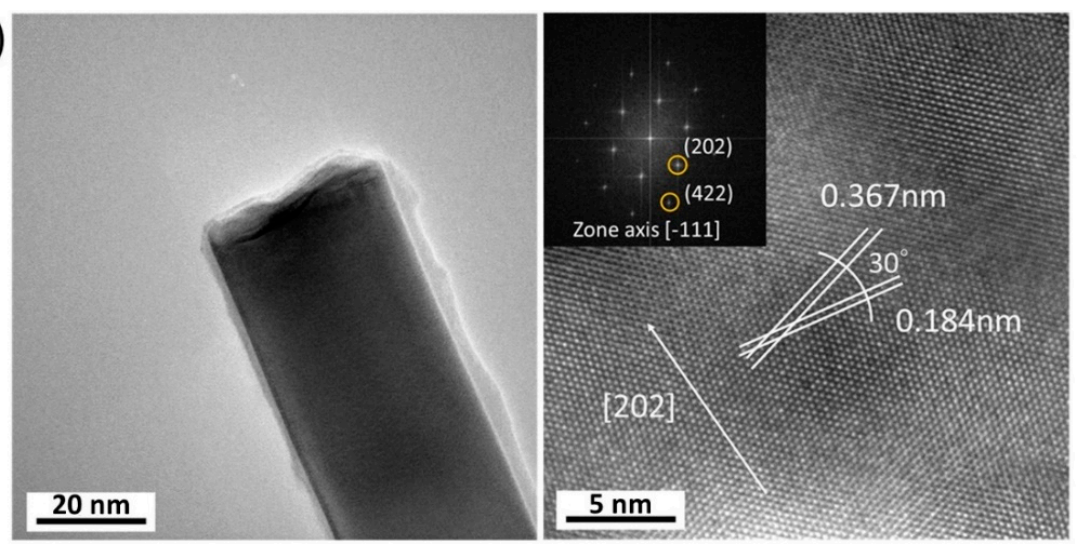

Figure 5. (a) XRD spectrums of $\beta-\mathrm{FeSi}_{2}$ and $\mathrm{FeSi}$ at different growth temperatures. (b) XRD spectrums of $\beta-\mathrm{FeSi}_{2}$ and $\mathrm{FeSi}$ at different ambient pressures. (c,d) Low-magnification TEM and HR-TEM images of $\mathrm{FeSi}$ and $\beta-\mathrm{FeSi}_{2}$ nanowires (NWs). (c) FeSi nanowires grown at $1000{ }^{\circ} \mathrm{C}$ for $5 \mathrm{~min}$. The inset shows the corresponding diffraction patterns of FeSi. (d) $\beta-\mathrm{FeSi}_{2}$ nanowires grown at $850{ }^{\circ} \mathrm{C}$ for $2 \mathrm{~h}$. The inset shows the corresponding diffraction patterns of $\beta-\mathrm{FeSi}_{2}$.

\subsection{Growth Mechanism}

In order to observe the concentration distribution in our experiment and connect the concentration to processing parameters and the phase that would form in the experiment, a method was utilized here. First, $\mathrm{Si}(100)$ substrates were replaced by $\mathrm{Al}_{2} \mathrm{O}_{3}$ substrates, and the substrates were put into crucibles $\mathrm{A}, \mathrm{B}$, and $\mathrm{C}$. Then, $\mathrm{FeCl}_{3}$ was deposited on $\mathrm{Al}_{2} \mathrm{O}_{3}$ substrates with different processing parameters. These $\mathrm{Al}_{2} \mathrm{O}_{3}$ substrates in the different crucibles were taken for element analysis by energy-dispersive X-ray spectroscopy (EDX, Bruker, Billerica, MA, USA), and the results are shown in Figure 6. The reaction concentration at $1000{ }^{\circ} \mathrm{C}$ was higher than that at 850 and $650{ }^{\circ} \mathrm{C}$; we found that the reaction concentration became lower when the flow rate increased. The results indicate that $\mathrm{FeSi}$ NWs were grown at high temperature, while no NWs appeared at a high flow rate. As we considered different deposition positions, at high flow rates (100 and $200 \mathrm{sccm})$, the concentration distribution was uniform; however, at low flow rates (10 and $20 \mathrm{sccm})$, the reaction concentration was higher in the crucible which was further away from the precursor. This may be attributed to the fact that in the experiment, the pump pulled out the gas in the quartz tube, making most of the $\mathrm{FeCl}_{3}$ molecules brought to the downstream. Thus, the probability for the precursor to deposit on the substrate in crucible $\mathrm{C}$ increased. The reactions of $\mathrm{FeCl}_{3}$ with silicon substrates to form $\beta-\mathrm{FeSi}_{2}$ and $\mathrm{FeSi}$ nanowires may follow the reaction pathways below, and the growth mechanisms are shown in Figure 7.

$\beta-\mathrm{FeSi}_{2}$ :

$$
\begin{gathered}
4 \mathrm{FeCl}_{3}(\mathrm{~g})+11 \mathrm{Si}(\mathrm{s}) \rightarrow 4 \beta-\mathrm{FeSi}_{2}+3 \mathrm{SiCl}_{4}(\mathrm{~g}) \\
2 \mathrm{FeCl}_{3}(\mathrm{~g})+4 \mathrm{SiCl}_{4}(\mathrm{~g}) \rightarrow 2 \beta-\mathrm{FeSi}_{2}+11 \mathrm{Cl}_{2}(\mathrm{~g})
\end{gathered}
$$

FeSi:

$$
\begin{gathered}
2 \mathrm{FeCl}_{3}(\mathrm{~s}) \leftrightarrow \mathrm{Fe}_{2} \mathrm{Cl}_{6}(\mathrm{~g}) \\
2 \mathrm{Fe}_{2} \mathrm{Cl}_{6}(\mathrm{~g})+7 \mathrm{Si}(\mathrm{s}) \rightarrow 4 \mathrm{FeSi}(\mathrm{s})+3 \mathrm{SiCl}_{4}(\mathrm{~g}) \\
\mathrm{Fe}_{2} \mathrm{Cl}_{6}(\mathrm{~g}) \leftrightarrow 2 \mathrm{FeCl}_{2}(\mathrm{~s})+\mathrm{Cl}_{2}(\mathrm{~g}) \\
\mathrm{FeCl}_{2}(\mathrm{~s})+\mathrm{Cl}_{2}(\mathrm{~g})+2 \mathrm{Si}(\mathrm{s}) \rightarrow \mathrm{FeSi}(\mathrm{s})+\mathrm{SiCl}_{4}(\mathrm{~g})
\end{gathered}
$$


(a)

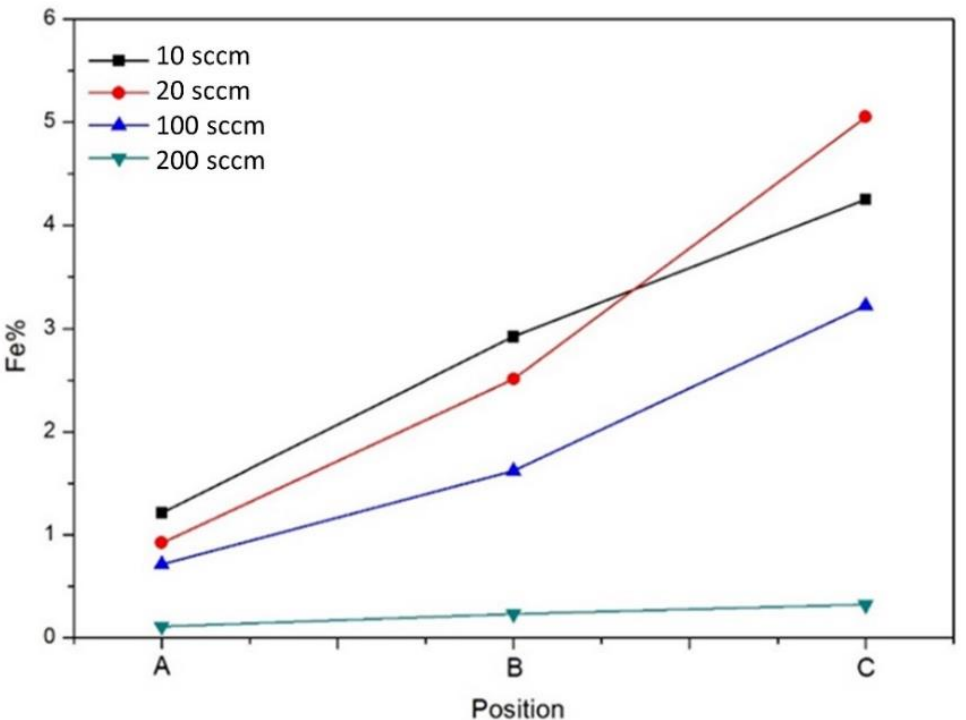

(b)

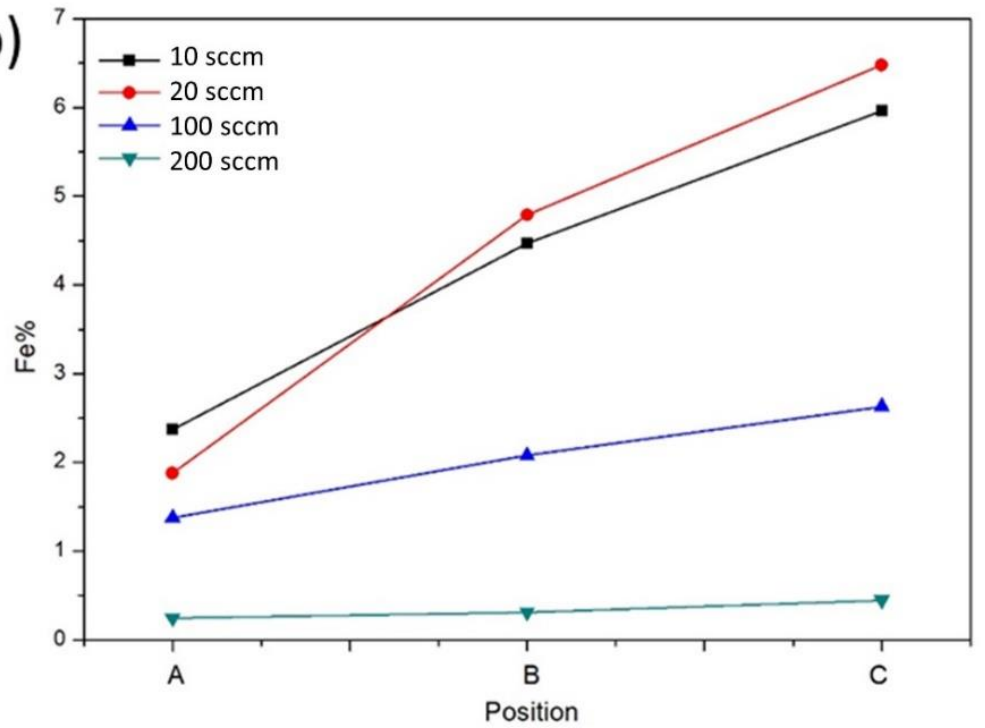

(c)

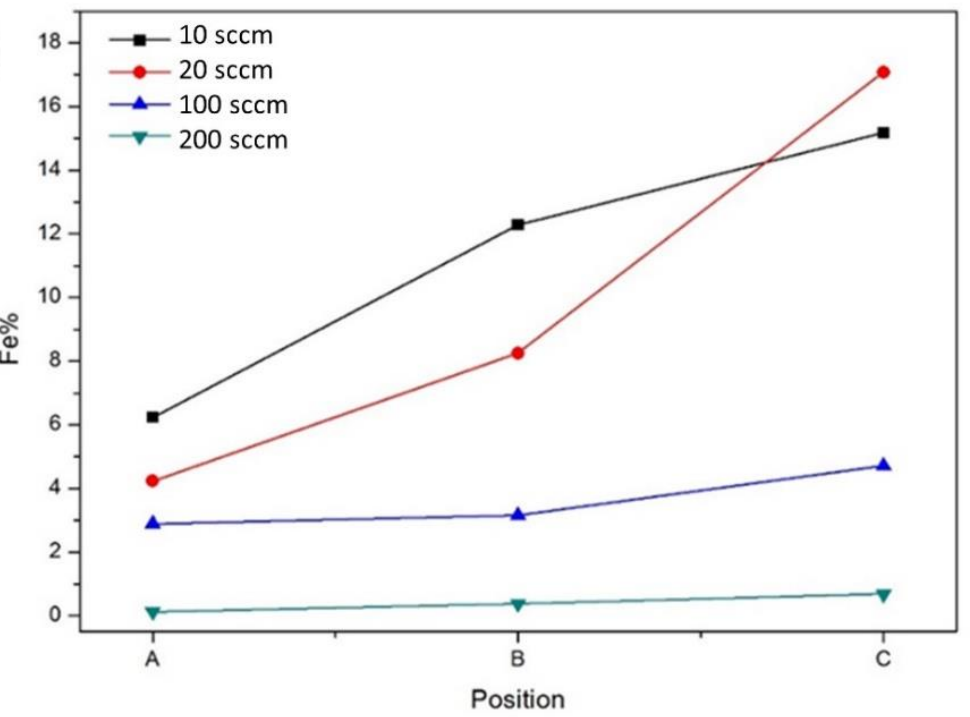

Figure 6. The EDX analysis of Fe on the substrate for different temperatures: (a) $650{ }^{\circ} \mathrm{C},(\mathbf{b}) 850{ }^{\circ} \mathrm{C}$, and (c) $1000{ }^{\circ} \mathrm{C}$. 


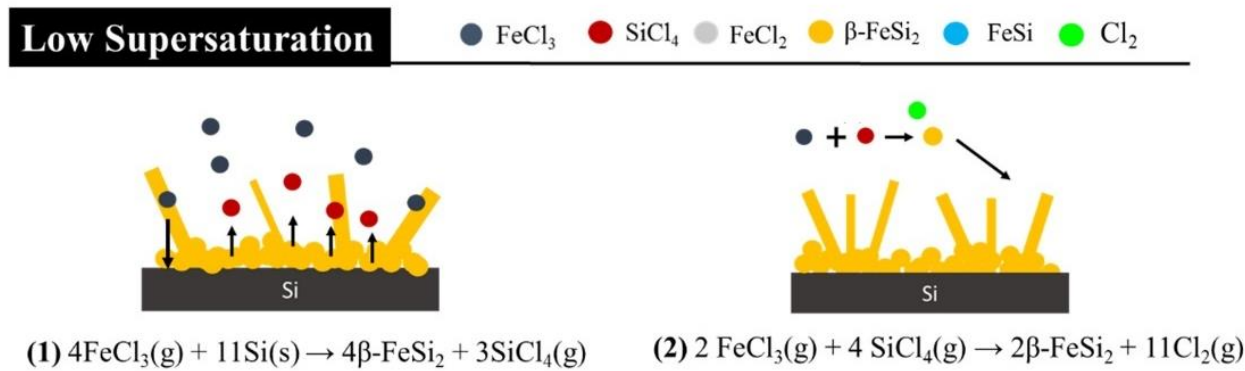

\section{High Supersaturation}

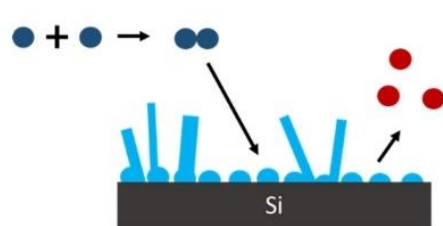

(3) $2 \mathrm{FeCl}_{3}(\mathrm{~s}) \leftrightarrow \mathrm{Fe}_{2} \mathrm{Cl}_{6}(\mathrm{~g})$ $2 \mathrm{Fe}_{2} \mathrm{Cl}_{6}(\mathrm{~g})+7 \mathrm{Si}(\mathrm{s}) \rightarrow 4 \mathrm{FeSi}(\mathrm{s})+3 \mathrm{SiCl}_{4}(\mathrm{~g})$

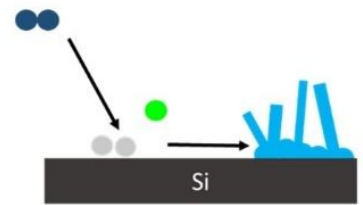

(4) $\mathrm{Fe}_{2} \mathrm{Cl}_{6}(\mathrm{~g}) \leftrightarrow 2 \mathrm{FeCl}_{2}(\mathrm{~s})+\mathrm{Cl}_{2}(\mathrm{~g})$ $\mathrm{FeCl}_{2}(\mathrm{~s})+\mathrm{Cl}_{2}(\mathrm{~g})+2 \mathrm{Si}(\mathrm{s}) \rightarrow \mathrm{FeSi}(\mathrm{s})+\mathrm{SiCl}_{4}(\mathrm{~g})$

Figure 7. The growth mechanism of iron silicide nanowires.

Through the reaction concentration analysis above, we found that a higher temperature at a lower flow rate would cause a higher concentration. The reaction concentration was the key to deciding which composition was formed. FeSi nanowires were fabricated in a high reaction concentration environment, while $\beta-\mathrm{FeSi}_{2}$ nanowires were fabricated in a low one. Lots of experimental evidence indicates that the mechanism of the nanowires' fabrication is a vapor-solid mechanism [32]. In our case, there were no catalyst particles or metal liquid droplets found on the tip of the nanowires, suggesting that the growth mechanism in our experiment was not a vapor-liquid-solid mechanism. There were several steps in the growth process of nanowires. First, the $\mathrm{FeCl}_{3}$ particles were deposited on the $\mathrm{Si}$ substrate, and formed silicide particles. Second, these particles agglomerated and formed thin films. Then, nanowires were grown from the heterogeneous nucleation sites on the surface of the thin films.

\section{Conclusions}

In this study, we synthesized two phases of iron silicide NWs via the CVD method, which were $\mathrm{FeSi}$ and $\beta-\mathrm{FeSi}_{2}$. The influence of processing parameters, such as temperature, ambient pressure, and gas flow rate were systematically investigated, and the growth mechanism was also proposed. The phase of NWs grown at $1000{ }^{\circ} \mathrm{C}$ was $\mathrm{FeSi}$, while that grown at $850{ }^{\circ} \mathrm{C}$ was $\beta-\mathrm{FeSi}_{2}$. The diameter of NWs became wider with the increase of ambient pressure. Gas flow rate affected the number and density of the NWs grown on the substrates; with a higher flow rate, the number of the NWs was reduced. The reason why these parameters influenced the results of our experiment was that all of them varied the reaction concentration in the furnace. A high temperature, low ambient pressure, and low gas flow rate would create an environment of high reaction concentration; the reaction time should be shortened to grow NWs on the substrate.

Author Contributions: W.-J.H. and K.-C.L. conceived the study and designed the research. W.-J.H. conducted the experiments. W.-J.H., Y.-Y.C., H.-M.H. and K.-C.L. wrote the manuscript. All authors read and approved the final manuscript.

Funding: This research was funded by Ministry of Science and Technology of Taiwan, grant number MOST 105-2628-E-006-002-MY3.

Conflicts of Interest: The authors declare no conflict of interest. 


\section{References}

1. Pham, C.V.; Repp, S.; Thomann, R.; Krueger, M.; Weber, S.; Erdem, E. Charge transfer and surface defect healing within $\mathrm{ZnO}$ nanoparticle decorated graphene hybrid materials. Nanoscale 2016, 8, 9682-9687. [CrossRef] [PubMed]

2. Erdem, E.; Kiraz, K.; Somer, M.; Eichel, R.A. Size effects in $\mathrm{Fe}^{3+}$-doped $\mathrm{PbTiO}_{3}$ nanocrystals-Formation and orientation of $\left(\mathrm{FeTi}^{\prime} \mathrm{VO}\right)$ defect-dipoles. J. Eur. Ceram. Soc. 2010, 30, 289-293. [CrossRef]

3. Park, S.; Lim, S.; Choi, H. Chemical Vapor Deposition of Iron and Iron Oxide Thin Films from Fe(II) Dihydride Complexes. Chem. Mater. 2006, 18, 5150-5152. [CrossRef]

4. Lu, C.M.; Hsu, H.F.; Lu, K.C. Growth of single-crystalline cobalt silicide nanowires and their field emission property. Nanoscale Res. Lett. 2013, 8, 308. [CrossRef] [PubMed]

5. Chiu, W.L.; Chiu, C.H.; Chen, J.Y.; Huang, C.W.; Huang, Y.T.; Lu, K.C.; Hsin, C.L.; Yeh, P.H.; Wu, W.W. Single-crystalline delta- $\mathrm{Ni}_{2} \mathrm{Si}$ nanowires with excellent physical properties. Nanoscale Res. Lett. 2013, 8, 290. [CrossRef] [PubMed]

6. Hsu, S.C.; Hsin, C.L.; Huang, C.W.; Yu, S.Y.; Wang, C.W.; Lu, C.M.; Lu, K.C.; Wu, W.W. Single-crystalline Ge nanowires and $\mathrm{Cu}_{3} \mathrm{Ge} / \mathrm{Ge}$ nano-heterostructures. CrystEngComm 2012, 14, 4570-4574. [CrossRef]

7. Lu, K.C.; Wu, W.W.; Ouyang, H.; Lin, Y.C.; Huang, Y.; Wang, C.W.; Wu, Z.W.; Huang, C.W.; Chen, L.J.; $\mathrm{Tu}, \mathrm{K} . \mathrm{N}$. The influence of surface oxide on the growth of metal/semiconductor nanowires. Nano Lett. 2011, 11, 2753-2758. [CrossRef] [PubMed]

8. Wu, W.W.; Lu, K.C.; Chen, K.N.; Yeh, P.H.; Wang, C.W.; Lin, Y.C.; Huang, Y. Controlled large strain of Ni silicide/Si/Ni silicide nanowire heterostructures and their electron transport properties. Appl. Phys. Lett. 2010, 97, 203110. [CrossRef]

9. Wu, W.W.; Lu, K.C.; Wang, C.W.; Hsieh, H.Y.; Chen, S.Y.; Chou, Y.C.; Yu, S.Y.; Chen, L.J.; Tu, K.N. Growth of multiple metal/semiconductor nanoheterostructures through point and line contact reactions. Nano Lett. 2010, 10, 3984-3989. [CrossRef] [PubMed]

10. Chou, Y.C.; Lu, K.C.; Tu, K.N. Nucleation and growth of epitaxial silicide in silicon nanowires. Mater. Sci. Eng. R Rep. 2010, 70, 112-125. [CrossRef]

11. Riffel, M.; Gross, E.; Stohrer, U. Electrical contacts for $\mathrm{FeSi}_{2}$ and higher manganese silicide thermoelectric elements. J. Mater. Sci. Mater. Electron. 1995, 6, 182-185. [CrossRef]

12. Rowe, D.M. CRC Handbook of Thermoelectrics; CRC Press: Boca Raton, FL, USA, 1995.

13. Jin, S.; Schmitt, A.L.; Zhu, L.; Song, Y.; Szcech, J. Synthesis, characterization, and physical properties of transition metal silicide nanowires. In Proceedings of the Nanomaterial Synthesis and Integration for Sensors, Electronics, Photonics, and Electro-Optics, Boston, MA, USA, 1-4 October 2006.

14. Preinesberger, C.; Vandre, S.; Kalka, T.; Dahne-Prietsch, M. Formation of dysprosium silicide wires on Si(001). J. Phys. D 1998, 31, L43-L45. [CrossRef]

15. Chen, L.J.; Wu, W.W. Metal silicide nanowires. Jpn. J. Appl. Phys. 2015, 54, 07JA04. [CrossRef]

16. Chen, Y.; Ohlberg, D.A.A.; Medeiros-Ribeiro, G.; Chang, Y.A.; Williams, R.S. Self-assembled growth of epitaxial erbium disilicide nanowires on silicon (001). Appl. Phys. Lett. 2000, 76, 4004-4006. [CrossRef]

17. Chen, Y.; Ohlberg, D.A.A.; Williams, R.S. Nanowires of four epitaxial hexagonal silicides grown on $\mathrm{Si}(001)$. J. Appl. Phys. 2002, 91, 3213-3218. [CrossRef]

18. Preinesberger, C.; Becker, S.K.; Vandre, S.; Kalka, T.; Dahne, M. Structure of DySi ${ }_{2}$ nanowires on Si(001). J. Appl. Phys. 2002, 91, 1695-1697. [CrossRef]

19. Stevens, M.; He, Z.; Smith, D.J.; Bennett, P.A. Structure and orientation of epitaxial titanium silicide nanowires determined by electron microdiffraction. J. Appl. Phys. 2003, 93, 5670-5674. [CrossRef]

20. Nogami, J.; Liu, B.Z.; Katkov, M.V.; Ohbuchi, C.; Birge, N.O. Self-assembled rare-earth silicide nanowires on Si(001). Phys. Rev. B 2001, 63, 233305. [CrossRef]

21. Lian, O.Y.; Thrall, E.S.; Deshmukh, M.M.; Park, H. Vapor-phase synthesis and characterization of epsilon-FeSi nanowires. Adv. Mater. 2006, 18, 1437-1440.

22. Schmitt, A.L.; Bierman, M.J.; Schmeisser, D.; Himpsel, F.J.; Jin, S. Synthesis and properties of single-crystal FeSi nanowires. Nano Lett. 2006, 6, 1617-1621. [CrossRef] [PubMed]

23. Borisenko, V.E. Semiconducting Silicides; Springer: Berlin, Germany, 2000.

24. Vonkanel, H.; Onda, N.; Sirringhaus, H.; Mullergubler, E.; Goncalvesconto, S.; Schwarz, C. Epitaxial phase transitions in the iron/silicon system. Appl. Surf. Sci. 1993, 70, 559-563. [CrossRef] 
25. Desimoni, J.; Bernas, H.; Behar, M.; Lin, X.W.; Washburn, J.; Lilientalweber, Z. Ion beam synthesis of cubic $\mathrm{FeSi}_{2}$. Appl. Phys. Lett. 1993, 62, 306-308. [CrossRef]

26. Alvarez, J.; Hinarejos, J.J.; Michel, E.G.; Miranda, R. Determination of the Fe/Si(111) phase diagram by means of photoelectron spectroscopies. Surf. Sci. 1993, 287, 490-494. [CrossRef]

27. Christensen, N.E. Electronic structure of beta-FeSi 2. Phys. Rev. B 1990, 42, 7148-7153. [CrossRef]

28. Leong, D.; Harry, M.; Reeson, K.J.; Homewood, K.P. A silicon/iron-disilicide light-emitting diode operating at a wavelength of $1.5 \mu \mathrm{m}$. Nature 1997, 387, 686. [CrossRef]

29. Manyala, N.; Sidis, Y.; DiTusa, J.F.; Aeppli, G.; Young, D.P.; Fisk, Z. Magnetoresistance from quantum interference effects in ferromagnets. Nature 2000, 404, 581-584. [CrossRef] [PubMed]

30. Menzel, A.; Goldberg, R.; Burshtein, G.; Lumelsky, V.; Subannajui, K.; Zacharias, M.; Lifshitz, Y. Role of carrier gas flow and species diffusion in nanowire growth from thermal CVD. J. Phys. Chem. C 2012, 116, 5524-5530. [CrossRef]

31. Hung, S.W.; Yeh, P.H.; Chu, L.W.; Chen, C.D.; Chou, L.J.; Wu, Y.J.; Chen, L.J. Direct growth of beta-FeSi 2 nanowires with infrared emission, ferromagnetism at room temperature and high magnetoresistance via a spontaneous chemical reaction method. J. Mater. Chem. 2011, 21, 5704-5709. [CrossRef]

32. Chang, C.M.; Chang, Y.C.; Chung, Y.A.; Lee, C.Y.; Chen, L.J. Synthesis and properties of the low resistivity tisi 2 nanowires grown with $\mathrm{TiF}_{4}$ precursor. J. Phys. Chem. C 2009, 113, 17720-17723. [CrossRef]

(C) 2018 by the authors. Licensee MDPI, Basel, Switzerland. This article is an open access article distributed under the terms and conditions of the Creative Commons Attribution (CC BY) license (http:/ / creativecommons.org/licenses/by/4.0/). 